\title{
PENERAPAN SISTEM TERINTEGRASI PANDUAN PARIWISATA BERBASIS MOBILE UNTUK PELAKU PARIWISATA DI KABUPATEN BULELENG DENGAN MODEL TAM
}

\author{
Ketut Agustini ${ }^{1}$, I Nengah Suparta ${ }^{2}$, I Made Gede Sunarya ${ }^{3}$, \\ I Made Agus Wirawan ${ }^{4}$ \\ 1,3,4 Jurusan Pendidikan Teknik Informatika, Fakultas Teknik dan Kejuruan \\ 2Jurusan Pendidikan Matematika, Fakultas MIPA \\ Universitas Pendidikan Ganesha \\ Singaraja, Indonesia \\ e-mail : eghee2006@gmail.com, isuparta@yahoo.com, \\ dek_naya@yahoo.com imade.aguswirawan@gmail.com
}

\begin{abstract}
Abstrak
Penelitian ini bertujuan untuk mengimplementasikan sistem terintegrasi untuk panduan pariwisata berbasis mobile yang telah dikembangkan pada tahun sebelumnya, sebagai daya dukung peningkatan pariwisata di Kabupaten Buleleng, serta melihat tingkat penerimaan teknologi para pelaku pariwisata terhadap sistem tersebut menggunakan Technology Acceptance Model (TAM). Penelitian dilakukan melalui observasi dan kuesioner terhadap tiga puluh responden yang mewakili unsur pelaku pariwisata seperti unsur dari dinas pariwisata, POK Darwis dan unsur PHRI. Ada persepsi kemudahan dalam penggunaan sistem (Perceived Ease of Use/PEOU), persepsi manfaat dari penggunaan sistem (Perceived Usefulness/PU), sikap pengguna terhadap sistem (Attitude Toward Using/ATT), dan penerimaan sistem oleh pengguna (Behavioral Intention to Use/ITU). Semua data diuji secara deskriptif kualitatif, Goodness of Fit test dan uji hipotesis. Ditemukan bahwa persepsi manfaat dan kemudahan penggunaan adalah faktor utama dalam menerapkan sistem terintegrasi panduan pariwisata berbasis mobile dan respon pelaku pariwisata terhadap sistem adalah positif.
\end{abstract}

Kata Kunci : Implementasi, sistem terintegrasi panduan pariwisata berbasis mobile, Technology Acceptance Model, kuesioner, pelaku pariwisata.

\footnotetext{
Abstract

This study aimed at implement an integrated system to guide mobile-based tourism that has developed in the previous year, as increased tourism carrying capacity in Buleleng regency, given the level of technology acceptance tourism actors of the system using the Technology Acceptance Model (TAM). The study was conducted through observation and questionnaires to thirty respondents who represents
} 
stakeholders in tourism as an element of the tourism department, POK Darwis and PHRI elements. There is a perceived ease of use the system (PEOU), perceived usefulness of the system (PU), Attitudes towards using the system (ATT), and Behavioral Intention to Use (ITU). All data were tested by qualitative descriptive, Goodness of Fit test and test hypotheses. It is found that perceptions of the benefits and ease of use is a major factor in implementing an integrated system based on mobile tourism guide tourism players and the response of the system is positive .

Keywords : implementation, integrated systems-based mobile tourism guide, Technology Acceptance Model (TAM), tourism actors.

\section{PENDAHULUAN}

Timpangnya pendapatan antara Bali Selatan dan Bali Utara yang tampak mencolok terlihat dari terfokusnya pengembangan pariwisata di Bali Selatan. Para wisatawan lebih mengenal daerah wisata Kuta di Kabupaten Badung dan Tanah Lot di Kabupaten Tabanan. Padahal Bali utara tidak kalah indahnya dengan daerah lain di Bali. Wilayahnya yang masih tradisional dan menyatu dengan alam dan kebudayaan yang ada memberikan suatu daya tarik tersendiri yang tidak dapat diperoleh wisatawan di daerah lain. Banyaknya usaha konservasi di berbagai daerah wisata di Bali Utara telah memberikan suatu nilai tambah akan keunikan yang membanggakan. Namun sangat disayangkan jika semua keindahan itu tidak dapat dinikmati oleh wisatawan yang datang ke Bali. Hal ini disebabkan karena masih kurangnya upaya pemerintah Bali untuk mempromosikan berbagai potensi wisata yang ada di wilayah Bali Utara agar dapat lebih siap menerima calon wisatawan baru. Wilayah Bali Utara yang berada paling jauh dari pusat kota seakan ditinggalkan begitu saja semenjak berpindahnya ibukota Bali dari kota Singaraja menjadi Denpasar.
Berkembangnya teknologi yang semakin pesat, pariwisata tidak hanya dapat diketahui melalui surat kabar, brosur ataupun majalah. Namun dapat diketahui melalui akses internet melalui web atau mobile. Dalam persoalan yang ada saat ini adalah pengoptimalan pemanfaatan teknologi mobile dalam aplikasi kepariwisataan belum dijalankan secara optimal dan dalam pencarian informasi masih belum menyajikan data-data yang lengkap dan memadai terutama informasi yang berhubungan dengan objek pariwisata beserta fasilitas-fasilitas umum terdekatnya. Oleh karena itu pemanfaatan teknologi mobile yang menekankan pada informasi pariwisata, sebagai panduan dan landasan dalam pengembangan pariwisata di Bali Utara merupakan hal yang harus diperhatikan. Perkembangan teknologi informasi melalui mobile di era ini meningkat dikarenakan banyak orang membutuhkan suatu sistem informasi yang mudah diakses serta bisa dibawa kemana-mana. Dengan banyaknya penyebaran teknologi mobile yang ada dan kemudahan yang ditawarkan akan sangat membantu jika para wisatawan dapat mengetahui informasi wisata tentang suatu daerah wisata yang akan dituju. 
Gelombang pembangunan akomodasi pariwisata di Bali terlihat pesat pasca studi masterplan pariwisata Bali oleh SCETO. Kebijakan yang diterapkan berdasarkan studi tersebut memang terbukti mampu meningkatkan kedatangan pariwisata secara signifikan dari tahun ke tahun. Konsekuensinya daerah kawasan segitiga emas (Badung, Gianyar dan Tabanan) tersebut mulai dipadati dengan investasi. Terjadi penumpukan pembangunan fasilitas pariwisata di daerah tersebut menyebabkan kepadatan penduduk serta kemacetan dimana-mana, sehingga membuat dampak yang tidak baik bagi dunia pariwisata ke depan. Sebaliknya, Kabupaten Buleleng yang memiliki wilayah paling luas diantara kabupatenkabupaten yang lain di Bali mendapat kunjungan wisatawan yang masih rendah. Data dinas pariwisata provinsi Bali 2011 diperoleh bahwa Kabupaten Buleleng selama lima tahun terakhir memiliki tingkat kunjungan wisatawan yang lebih rendah dibandingkan dengan Kota Denpasar dan Kabupaten Gianyar. Padahal dari segi jumlah dan nilai, Kabupaten Buleleng memiliki Daya Tarik Wisata (DTW) yang paling banyak (38 DTW) dibandingkan dengan Kota Denpasar (13 DTW) dan Kabupaten Gianyar (16 DTW). Kalau ketimpangan pembangunan pariwisata ini dibiarkan tentu akan membawa dampak-dampak negatif terhadap pariwisata Bali. Pujaastawa, et al (2005:4) mengemukakan dampak-dampak negatif tersebut berupa makin meningkatnya kesenjangan ekonomi antara Bali Selatan dengan wilayah Bali lainnya, kepadatan penduduk, persaingan hidup serta ancaman terhadap lingkungan.

Adapun upaya yang dilakukan untuk mendukung percepatan pembangunan pariwisata adalah dengan mengintegrasikan bisnis pariwisata dan teknologi menjadi satu dengan harapan dapat menunjang dan bersinegi utuh. Hal ini memunculkan perlunya berbagai macam sarana promosi tempat-tempat pariwisata di Kabupaten Buleleng, salah satunya dengan sarana internet mobile. Dengan teknologi ini diharapkan dapat memperlihatkan kepada banyak orang, terutama para wisatawan sisi lain dari Pulau Bali, keindahan yang belum terpublikasikan dengan baik karena pemerintah yang masih terfokus kepada apa yang sudah dikenal oleh masyarakat dunia. Melalui sistem yang terintegrasi ini diharapkan dapat membuka wawasan masyarakat/ wisatawan bahwa Bali juga memiliki daerah utara yang indah. Mengubah pikiran wisatawan untuk dapat melihat keindahan yang tersembunyi di wilayah Bali Utara dengan cara mengeksplorasi alam.

Selain itu dengan adanya promosi ini, dapat meremajakan kembali citra pulau Bali di mata Internasional dengan berbagai hal baru yang terdapat di wilayah utara, dan tentunya diharapkan melalui publikasi ini dapat meningkatkan jumlah kunjungan wisata dan juga investor untuk membangun wilayah Bali Utara menjadi Bali yang berbeda dengan wilayah di selatan Bali. Menjadikan wilayah Bali Utara sebagai masa depan Bali.

Tentu dengan semakin dikenalnya wilayah Bali Utara, hal ini dapat membantu pemerataan jumlah 
kunjungan wisatawan di Pulau Bali, sehingga hal ini dapat menguntungkan masyarakat di wilayah Bali Utara, dan juga bisa membantu memecahkan permasalahan kepadatan aktivitas di wilayah Bali selatan. Menjadikan Bali tetap sebagai pulau yang indah dan mempesona.

Pengembangan sebuah sistem terintegrasi panduan pariwisata berbasis mobile telah dilakukan pada tahun sebelumnya dan sudah melalui beberapa tahapan validasi sistem, namun yang menjadi kendala umum dalam pengembangan sebuah sistem adalah lambatnya proses adopsi masyarakat terhadap sebuah sistem. Keberlangsungan pengembangan sistem sangatlah bergantung pada penerimaaan pengguna terhadap Implementasi Sistem Terintegrasi Panduan Pariwisata Berbasis Mobile (disingkat dengan istilah SISTERPANTASI-MOBI) saat ini, karena tanpa memperhatikan itu proses keberlanjutan pengembangan akan menjadi sia-sia dan bahkan hanya akan menimbulkan akumulasi kegagalan sistem. Banyak faktor yang mempengaruhi penerimaan pengguna salah satunya adalah aspek perilaku (Nasution, 2004, h. 1).

Implementasi SISTER-PANTASIMOBI telah dilakukan melalui workshop terhadap beberapa unsur pelaku pariwisata seperti unsur Pemerintah Daerah yang diwakili dari Dinas Pariwisata Budaya dan Dinas Depkominfo, yang berfungsi sebagai administrator sistem, serta dari unsur kelompok Sadar Wisata (POK DARWIS) dan PHRI Kabupaten Buleleng. Agar sistem yang telah diterapkan dan digunakan dapat diketahui responnya, maka perlu dilakukan evaluasi dengan menggunakan teori perilaku (behavioral theory). Ada banyak jenis teori perilaku untuk mengkaji proses adopsi teknologi informasi, namun Technology Acceptance Model (TAM) merupakan model penelitian yang paling banyak digunakan untuk tujuan tersebut (Hermana,2005, h.455). Model TAM dilandaskan pada penerimaan pengguna dalam melakukan adopsi teknologi, karena penerimaan pengguna menjadi faktor penting yang menentukan sukses atau gagalnya pengerjaan sistem informasi.

Menurut Davis (1989), tujuan utama TAM adalah untuk memberikan penjelasan tentang penerimaan teknologi secara umum, memberikan penjelasan tentang perilaku/sikap pengguna dalam suatu populasi

Beberapa model yang dibangun untuk menganalisis dan memahami faktor-faktor yang mempengaruhi diterimanya penggunaan teknologi komputer, diataranya yang tercatat dalam berbagai literatur dan referensi hasil riset dibidang teknologi informasi adalah seperti Theory of Reasoned Action (TRA), Theory of Planned Behaviour (TPB), dan Technology Acceptance Model (TAM).

Model TAM sebenarnya diadopsi dari model TRA yaitu teori tindakan yang beralasan dengan satu premis bahwa reaksi dan persepsi seseorang terhadap sesuatu hal, akan menentukan sikap dan perilaku orang tersebut (Davis,1989). Reaksi dan persepsi pengguna Teknologi Informasi (TI) akan mempengaruhi sikapnya dalam penerimaan terhadap teknologi tersebut. Salah satu faktor yang dapat mempengaruhinya adalah persepsi pengguna terhadap kemanfaatan dan 
kemudahan penggunaan TI sebagai suatu tindakan yang beralasan dalam konteks pengguna teknologi, sehingga alasan seseorang dalam melihat manfaat dan kemudahan penggunaan TI menjadikan tindakan/perilaku orang tersebut sebagai tolok ukur dalam penerimaan sebuah teknologi.

Model TAM yang dikembangkan dari teori psikologis, menjelaskan perilaku pengguna komputer yaitu berlandaskan pada kepercayaan (belief), sikap (attitude), keinginan (intention), dan hubungan perilaku pengguna (user behaviour relationship). Tujuan model ini untuk menjelaskan faktor-faktor utama dari perilaku pengguna terhadap penerimaan pengguna teknologi. Secara lebih terinci menjelaskan tentang penerimaan TI dengan dimensi-dimensi tertentu yang dapat mempengaruhi diterimanya TI oleh pengguna (user).

Model ini menempatkan faktor sikap dari tiap-tiap perilaku pengguna dengan dua variabel yaitu,

1. kemudahan penggunaan (ease of use)

2. kemanfaatan (usefullness)

Kedua variabel ini dapat menjelaskan aspek keperilakuan pengguna (Davis,1989). Kesimpulannya adalah model TAM dapat menjelaskan bahwa persepsi pengguna akan menentukan sikapnya dalam kemanfaatan penggunaan TI. Model ini secara lebih jelas menggambarkan bahwa penerimaan

penggunaan $\mathrm{TI}$ dipengaruhi oleh kemanfaatan (usefulness) dan kemudahan penggunaan (ease of use).

Penelitian ini menggunakan 4 (empat) konstruk yang telah dimodifikasi dari model penelitian TAM sebelumnya yaitu: Persepsi tentang kemudahan penggunaan (Perceived Ease Of Use), persepsi terhadap kemanfaatan (Perceived Usefulness), sikap penggunaan (Attitude Toward Using), dan perilaku untuk tetap menggunakan (Behavioral Intention To Use),

1. Perceived Ease of Use (PEOU)

Persepsi tentang kemudahan penggunaan sebuah teknologi didefinisikan sebagai suatu ukuran dimana seseorang percaya bahwa komputer dapat dengan mudah dipahami dan digunakan (Davis, 1989).

Beberapa indikator kemudahan penggunaan teknologi informasi, meliputi:

a.Komputer sangat mudah dipelajari

b.Komputer mengerjakan dengan mudah apa yang diinginkan oleh pengguna

c.Komputer sangat mudah untuk meningkatkan keterampilan pengguna

d.Komputer sangat mudah untuk dioperasikan

2. Perceived Usefulness (PU)

Persepsi terhadap kemanfaatan didefinisikan sebagai suatu ukuran dimana penggunaan suatu teknologi dipercaya akan mendatangkan manfaat bagi orang yang menggunakannya (Davis, 1989). Dimensi tentang kemanfaatan teknologi informasi meliputi:

a. Kegunaan, meliputi dimensi: menjadikan pekerjaan lebih mudah, bermanfaat, menambah produktivitas

b. Efektivitas, meliputi dimensi: mempertinggi efektivitas, mengembangkan kinerja pekerjaan 
3. Behavioral Intention to Use (ITU)

Behavioral Intention to Use adalah kecenderungan perilaku untuk tetap menggunakan suatu teknologi. Tingkat penggunaan sebuah teknologi komputer pada seseorang dapat diprediksi dari sikap perhatiannya terhadap teknologi tersebut, misalnya keinginanan menambah peripheral pendukung, motivasi untuk tetap menggunakan, serta keinginan untuk memotivasi pengguna lain (Davis, Fred D, 1989).

\section{Attitude Toward Using (ATT)}

Attitude Toward Using dalam TAM dikonsepkan sebagai sikap terhadap penggunaan sistem yang berbentuk penerimaan atau penolakan sebagai dampak bila seseorang menggunakan suatu teknologi dalam pekerjaannya (Davis,1989). Peneliti lain menyatakan bahwa faktor sikap (attitude) sebagai salah satu aspek yang mempengaruhi perilaku individual. Sikap seseorang terdiri atas unsur kognitif/cara pandang (cognitive), afektif (affective), dan komponen-komponen yang berkaitan dengan perilaku (behavioral components) (Nasution,2004).

\section{METODE}

Metode yang digunakan dalam penelitian ini adalah metode pengujian (evaluasi) sistem dengan mengukur tingkat penerimaan sistem berdasarkan persepsi pengguna menggunakan TAM. Pengumpulan data dilakukan melalui pengamatan (observasi) dan penyebaran angket/kuesioner terhadap 30 peserta pelatihan. Teknik analisis data yang digunakan adalah deskriptif kualitatif, Goodness of Fit test dan uji hipotesis dengan menggunakan SPSS13.0

Jenis data yang digunakan dalam penelitian ini adalah jenis data primer dengan kuesioner menggunakan skala linkert (skala 1-5). Kuesioner dikembangkan berdasarkan model TAM menurut Davis, Fred D. Variabel yang digunakan terdiri dari variabel dependent dan variabel independent. Variabel dependent (terikat) adalah (1) sikap terhadap penggunaan sistem yang berbentuk Penerimaan dan penolakan sistem (Attitude Toward Using/ATT), sedangkan variabel independent adalah (2) Persepsi kemudahan penggunaan sistem (Perceived Ease Of Use/PEOU), (3) Persepsi Kemudahan penggunaan sistem (Perceived Usefulness/PU) dan (4) kecenderungan perilaku untuk tetap menggunakan sistem (Behavioral Intention to Use/ITU).

Kerangka penelitian yang digunakan sebagai landasan teoritis dalam penyusunan hipotesis secara umum terbagi dalam empat variable diatas. Berdasarkan Gambar 1, serangkaian hipotesis yang akan diuji, yaitu : 


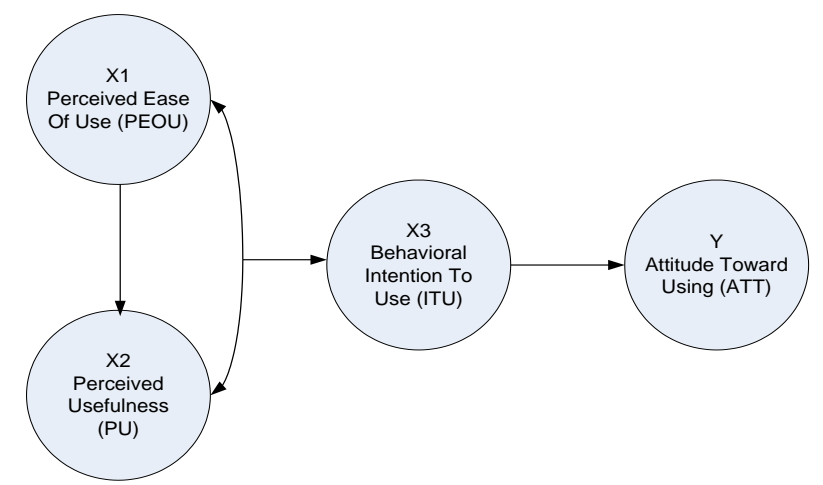

Gambar 1. Konstelasi Hubungan antar variabel

Hipotesis 1:

$\mathrm{H}_{0}$ : Persepsi Kemudahan (PEOU) dalam penggunaan Sister Pantasi Mobi tidak berpengaruh terhadap persepsi manfaat (PU) dari penggunaan Sister Pantasi Mobi

$\mathrm{H}_{1} \quad$ : Persepsi Kemudahan (PEOU) dalam penggunaan Sister Pantasi Mobi berpengaruh terhadap persepsi manfaat (PU) dari penggunaan Sister Pantasi Mobi

Hipotesis 2 :

$\mathrm{H}_{\mathrm{o}} \quad$ : Persepsi Kemudahan (PEOU) dalam penggunaan Sister Pantasi Mobi dan persepsi manfaat (PU) dari penggunaan Sister Pantasi Mobi tidak berpengaruh terhadap kecenderungan perilaku untuk tetap menggunakan (ITU) Sister Pantasi Mobi

$\mathrm{H}_{1} \quad$ : Persepsi Kemudahan (PEOU) dalam penggunaan Sister Pantasi Mobi dan persepsi manfaat (PU) dari penggunaan Sister Pantasi Mobi berpengaruh terhadap kecenderungan perilaku untuk tetap menggunakan (ITU) Sister Pantasi Mobi

Hipotesis 3 :

$\mathrm{H}_{0} \quad$ : Persepsi Kemudahan (PEOU) dalam penggunaan Sister Pantasi Mobi, persepsi manfaat (PU) dari penggunaan Sister Pantasi Mobi dan kecenderungan perilaku untuk tetap menggunakan (ITU) Sister Pantasi Mobi tidak berpengaruh terhadap sikap menerima atau menolak menggunakan (ATT) Sister Pantasi Mobi

$\mathrm{H}_{1} \quad$ : Persepsi Kemudahan (PEOU) dalam penggunaan Sister Pantasi Mobi, persepsi manfaat (PU) dari penggunaan Sister Pantasi Mobi dan kecenderungan perilaku untuk tetap menggunakan (ITU) Sister Pantasi Mobi berpengaruh terhadap sikap menerima atau menolak menggunakan (ATT) Sister Pantasi Mobi. 
Hipotesis 4 :

$\mathrm{H}_{\mathrm{o}}$ :Semua variabel independent (PEOU, PU dan ITU) secara simultan tidak berpengaruh terhadap variabel dependent (ATT) $\mathrm{H}_{1}$ :Semua variabel independent (PEOU, PU dan ITU) secara simultan berpengaruh terhadap variabel dependent (ATT)

\section{HASIL DAN PEMBAHASAN}

Tujuan khusus yang ingin dicapai dalam penelitian ini adalah Mengimplementasikan sistem terintegrasi untuk panduan pariwisata berbasis mobile sebagai daya dukung dalam meningkatkan pariwisata di Kabupaten Buleleng dan Mengukur tingkat penerimaan (adopsi teknologi) sistem berdasarkan persepsi pelaku pariwisata di Kabupaten Buleleng. Hasil analisis data menunjukkan bahwa,

1. Dengan melihat hasil probabilitas (signifikasi) $=0.00<0.05 \rightarrow$ maka $\mathrm{H}_{0}$ ditolak artinya $\mathrm{H}_{1}$ diterima, ini berarti Persepsi Kemudahan (PEOU) dalam penggunaan Sister Pantasi Mobi berpengaruh terhadap persepsi manfaat (PU) dari penggunaan Sister Pantasi Mobi (tabel 1)

Tabel 1. PEOU to PU

ANOVA ${ }^{b}$

\begin{tabular}{|c|c|c|c|c|c|c|}
\hline & & $\begin{array}{l}\text { Sum of } \\
\text { Squares }\end{array}$ & $\mathrm{df}$ & Mean Square & $\mathrm{F}$ & Sig. \\
\hline \multirow[t]{3}{*}{1} & Regression & 116.198 & 1 & 116.198 & 37.325 & $.000^{\mathrm{a}}$ \\
\hline & Residual & 87.168 & 28 & 3.113 & & \\
\hline & Total & 203.367 & 29 & & & \\
\hline
\end{tabular}

a. Predictors: (Constant), PEOU

b. Dependent Variable: PU

2. Dengan melihat hasil probabilitas (signifikasi) $=0.00<0.05 \rightarrow$ maka $\mathrm{H}_{0}$ ditolak artinya $\mathrm{H}_{1}$ diterima, ini berarti Persepsi Kemudahan (PEOU) dalam penggunaan Sister Pantasi Mobi dan persepsi manfaat
(PU) dari penggunaan Sister Pantasi Mobi berpengaruh terhadap kecenderungan perilaku untuk tetap menggunakan (ITU) Sister Pantasi Mobi. (tabel 2)

Tabel 2. PEOU and PU to ITU

ANOVA

\begin{tabular}{|rl|r|r|r|r|r|}
\hline \multicolumn{1}{|c|}{} & \multicolumn{1}{|c|}{ Sum of } & & & & \\
\hline 1 & Squares & df & Mean Square & \multicolumn{1}{c|}{$\mathrm{F}$} & \multicolumn{1}{c|}{ Sig. } \\
\hline & Regression & 38.882 & 2 & 19.441 & 75.151 & $.000^{\mathrm{a}}$ \\
& Residual & 6.985 & 27 & .259 & & \\
& Total & 45.867 & 29 & & & \\
\hline
\end{tabular}

a. Predictors: (Constant), PU, PEOU

b. Dependent Variable: ITU 
3. Dengan melihat hasil probabilitas $($ signifikasi) $=0.00<0.05 \rightarrow$ maka $\mathrm{H}_{0}$ ditolak artinya $\mathrm{H}_{1}$ diterima, ini berarti Persepsi Kemudahan (PEOU) dalam penggunaan Sister Pantasi Mobi, persepsi manfaat (PU) dari penggunaan Sister Pantasi Mobi dan kecenderungan perilaku untuk tetap menggunakan (ITU) Sister Pantasi Mobi berpengaruh terhadap sikap menerima atau menolak menggunakan (ATT) Sister Pantasi Mobi (tabel 3).

Tabel 3. PEOU, PU, and ITU to ATT

ANOVA ${ }^{b}$

\begin{tabular}{|c|c|c|c|c|c|c|}
\hline \multicolumn{2}{|c|}{ Model } & $\begin{array}{l}\text { Sum of } \\
\text { Squares }\end{array}$ & $\mathrm{df}$ & Mean Square & $\mathrm{F}$ & Sig. \\
\hline \multirow[t]{3}{*}{1} & Regression & 53.230 & 3 & 17.743 & 56.698 & $.000^{a}$ \\
\hline & Residual & 8.137 & 26 & .313 & & \\
\hline & Total & 61.367 & 29 & & & \\
\hline
\end{tabular}

a. Predictors: (Constant), ITU, PEOU, PU

b. Dependent Variable: ATT

4. Dengan melihat hasil probabilitas (signifikasi) $=0.00<0.05 \rightarrow$ maka $\mathrm{H}_{0}$ ditolak artinya $\mathrm{H}_{1}$ diterima, ini berarti Persepsi Kemudahan (PEOU) dalam penggunaan Sister Pantasi Mobi, persepsi manfaat (PU) dari penggunaan Sister Pantasi Mobi dan kecenderungan perilaku untuk tetap menggunakan (ITU) Sister Pantasi Mobi berpengaruh terhadap sikap menerima atau menolak menggunakan (ATT) Sister Pantasi Mobi. Dapat disimpulkan, secara simultan semua variabel independent berpengaruh terhadap variabel dependent (tabel 4).

Tabel 4. PEOU, PU and ITU (bersama-sama) to ATT

Model Summary

\begin{tabular}{|c|c|c|c|c|c|c|c|c|c|c|}
\hline \multirow[b]{2}{*}{ Model } & \multirow[b]{2}{*}{$\mathrm{R}$} & \multirow[b]{2}{*}{$R$ Square } & \multirow[b]{2}{*}{$\begin{array}{l}\text { Adjusted } \\
\text { R Square }\end{array}$} & \multirow[b]{2}{*}{$\begin{array}{l}\text { Std. Error of } \\
\text { the Estimate }\end{array}$} & \multicolumn{5}{|c|}{ Change Statistics } & \multirow[b]{2}{*}{$\begin{array}{l}\text { Durbin- } \\
\text { Watson }\end{array}$} \\
\hline & & & & & $\begin{array}{l}\text { R Square } \\
\text { Change }\end{array}$ & F Change & df 1 & $\mathrm{df} 2$ & Sig. F Change & \\
\hline 1 & $.931^{\mathrm{a}}$ & .867 & .852 & .55941 & .867 & 56.698 & 3 & 26 & .000 & 2.290 \\
\hline
\end{tabular}

a. Predictors: (Constant), ITU, PEOU, PU

b. Dependent Variable: ATT

Dari hasil pengujian hipotesis terlihat bahwa masing-masing variabel saling mempengaruhi satu dengan yang lainnya. Kebermanfaatan sistem dapat menjadi alasan utama bagi pelaku pariwisata untuk menerapkan 
sister pantasi mobi sebagai wadah untuk mempromosikan pariwisata yang ada di Kabupaten Buleleng. Mereka juga merasakan kemudahan penggunaan sistem sehingga perlu ditindaklanjuti secara serius oleh Pemerintah Daerah demi perkembangan pariwisata kedepan. Hal ini ditunjukkan dari komentar melalui kuesioner yang diberikan serta antusiasme para peserta workshop pada sesi diskusi/tanya-jawab. Kemudian kemudahan penggunaan dan manfaat sistem berpengaruh terhadap kecenderungan perilaku untuk tetap menggunakan sistem, ini berarti bahwa pelaku pariwisata menyadari di era kompetisi global manfaat dari IT khususnya sister pantasi mobi sangatlah besar bagi bisnis pariwisata, maka dari itu kecenderungan prilaku adalah tetap untuk berpromosi menggunakan IT.

Selanjutnya melalui kemudahan penggunaan, manfaat yang dirasakan serta kecenderungan untuk tetap menggunakan sistem berpengaruh terhadap sikap menerima/menolak sistem tersebut, artinya pengguna sudah merasakan dampak positif dari penerapan sister pantasi mobi terhadap promosi pariwisata. Untuk keberlanjutan sistem yang dikembangkan ini, diperlukan peran nyata pemerintah daerah untuk merealisasikan infrastruktur yang diperlukan masyarakat dan pelaku pariwisata khususnya dalam mengimplementasikan secara real sister pantasi mobi yang telah dihibahkan peneliti kepada Pemerintah Kabupaten Buleleng melalui Dinas Komunikasi dan Informasi sebagai penyedia layanan Informasi serta Dinas
Pariwisata dan Budaya Kabupaten Buleleng.

\section{SIMPULAN DAN SARAN}

Berdasarkan hasil pengembangan dan pengujian hipotesis sistem terintegrasi panduan pariwisata berbasis mobile yang telah dilakukan, dapat disimpulkan bahwa Aplikasi sistem terintegrasi panduan pariwisata berbasis mobile dapat menjalankan fungsionalitas yang dibutuhkan dalam mencari info-info daerah pariwisata di Kabupaten Buleleng secara detail, beserta fasilitas umum terdekatnya. Dari hasil uji hipotesis diperoleh bahwa persepsi manfaat dan kemudahan penggunaan adalah faktor utama dalam menerapkan sistem terintegrasi panduan pariwisata berbasis mobile dan respon pelaku pariwisata terhadap sistem adalah positif.

Saran bagi pengembangan lebih lanjut adalah Pengembangan sistem terintegrasi panduan pariwisata berbasis mobile ini kedepannya agar lebih bervariasi bidang pengembangannya juga dari segi fiturfiturnya seperti push service sehingga pengguna tidak merasa bosan dalam menggunakan aplikasi ini dan perlu ditambahkan fasilitas Global Positioning System (GPS) sehingga pengguna mendapatkan informasi mengenai lokasi fasilitas umum terdekat dari current posisi pengguna.

\section{DAFTAR PUSTAKA}

Davis, Fred D., 1989, Measurement Scales for Perceived Usefulness and Perceived Ease of Use, http://wings.buffalo.edu/mgmt/course 
/mgtsand/success/davis.html, (diakses 26 April 2013)

Hermana, B. 2005. Model Penerimaan

Teknologi Informasi dan Komunikasi: Meta Analysis. Paper presented at the Konferensi Nasional Teknologi Informasi dan Komunikasi Indonesia, ITB.

Nasution, F. N. 2004. Penggunaan

Teknologi Informasi Berdasarkan Aspek Perilaku (Behavioral Aspect).
Sumatera Utara: Universitas Sumatera Utara (USU).

Pujaastawa, Wirawan \& Adhika,2005, Pariwisata Terpadu, Alternatif Model Pengembangan Pariwisata Bali Tengah, Univ. Udayana Denpasar.

Zoran Vucetic, 2010, Mobile School Service (MSS); International Journal of Interactive Mobile Technologies volume 4 issue 2 